Revista Complutense de Educación

ISSNe: 1988-2793

http://dx.doi.org/10.5209/RCED.61498

\title{
Cómo Educar Adolescentes con Valores
}

Autora: Deanna Marie Mason

Editorial: LID Editorial Empresarial

Año de publicación: 2017

Número de páginas: 251

ISBN: 978-84-1689-466-6

Sin dudarlo, este documento se convierte en el libro de cabecera de cualquier madre o padre comprometido con la educación de sus hijos, como praxis preventiva de futuros comportamientos inadecuados en el proceso de maduración, desde el nacimiento hasta la adolescencia (periodo de transición a la vida adulta). Para ello, la autora ha generado un modelo denominado Paternidad Proactiva. Decía un amigo y pedagogo, "la mejor manera de que una persona no sea "mala', es evitando que lo sea" y, por tanto, se deben poner los medios y conseguir el caldo de cultivo apropiado. En esta idea se centra la paternidad proactiva que, en palabras de la autora, consiste "en dirigir y conducir a los padres hacia la obtención de resultados finales deseados en la educación de sus hijos, reconociendo y respetando su naturaleza única e individual".

El documento se divide en dos partes y un anexo. La primera parte trata de generalidades y la puesta en escena de elementos identificadores, propios de hijos en la edad más comprometida de sus vidas que es la adolescencia. Con buen criterio, la autora denomina esta primera parte como "Mi hijo, ese gran desconocido", donde se responden preguntas que algunos padres podrían hacerse: ¿Qué buscan nuestros hijos? ¿Cuáles son sus necesidades? ¿De qué son capaces nuestros hijos? ¿En que etapa del desarrollo se encuentra mi hijo? En definitiva, dar respuesta a dudas que en cada familia encajan de manera diferente, pues la heterogeneidad de las familias de hoy día es tan amplia, que también requiere de respuestas sin formato receta, para cada una de las necesidades, pues, como bien dice la autora, cada familia es única y especial.

Esta primera parte se divide en tres capítulos. El primer capítulo es una puesta en escena de los cambios de rol que también sufren los padres, en función de la evolución y maduración de sus hijos, desde la infancia hasta la adolescencia. El segundo capítulo permite reconocer las diferencias entre la madurez e inmadurez de los jóvenes, respecto a su edad cronológica. Téngase en cuenta que pocas veces van unidas las edades cronológicas y madurativas de las personas. Además, se plantean herramientas de control para identificar como los adolescentes se evaden de sus responsabilidades o en su caso, es una cuestión de inmadurez y, por tanto, necesita de su tiempo y del apoyo y orientación pertinente. El tercer capítulo tiene un carácter más informativo y orientador para los padres, pues se definen las diferentes etapas de desarrollo y las características físicas, emocionales, intelectuales, psicosociales y morales, desde la infancia a la adolescencia. Este apartado es muy clarificador para comprender e identificar en qué momento se encuentran nuestros hijos y, así, poder actuar en consecuencia. 
La segunda parte trata sobre la metodología o el modelo de educación, denominado Paternidad Proactiva. Consta de siete capítulos de lo más interesantes. El cuarto y quinto capítulo se centran en definir y orientar sobre la paternidad proactiva. En palabras de la autora, "ser padre proactivo implica prevenir o limitar los problemas de conducta, a la vez que transmitir valores éticos y morales de la familia para educar niños felices y sanos". Y dicha proactividad consiste en fijar límites, sentimiento de confianza y de control y técnicas parentales flexibles. Para ello, es clave conocer y comprender el desarrollo natural de nuestros hijos, para maximizar el impacto de la educación de los padres. El capítulo sexto, ahonda en la teoría de la paternidad proactiva, identificando los modos de aplicación de las técnicas de paternidad proactiva, a partir de las tres características fundamentales del modelo: fijar límites, técnicas flexibles, sentimiento de confianza y control. El séptimo capítulo identifica las fases o pasos para la consecución del modelo, centrado en tres principios básicos: seguridad, coherencia y responsabilidad compartida. En el capítulo octavo se proporcionan unas recomendaciones para padres, en su misión de guías, para favorecer la madurez de los hijos, a partir del ciclo vital de desarrollo de los adolescentes, que va desde identificar una característica que les interese, la selección de un guía que conecte y tenga dicha característica, búsqueda de una relación recíproca y por ende, pasar tiempo con dicho guía, probar que dicha característica funciona y conecta consigo mismo, hasta evaluar esta característica en sí mismo y comprobar si la mantiene, la modifica o la desecha. Y en estos procesos, los padres pueden ser ese guía y tener esa característica que permite conseguir una conexión y vinculación positiva, pero también pueden ser otros adultos y en eso, los padres, deben aceptarlo y comprenderlo. El capítulo noveno hace honor al modelo preventivo, desterrando la corrección como medida educativa, recordando la importancia de los límites y la disciplina, como fomento de la autoestima y el buen concepto de sí mismos, en todas y cada una de las etapas de maduración de los hijos. Y finalmente, en el décimo capítulo se presentan algunos de los fantasmas y preocupaciones que quitan el sueño a multitud de padres: consumo de sustancias poco o nada saludables, las dietas 'milagrosas', internet y redes sociales (sexting, ciberacoso, adición a videojuegos, uso irracional e incontrolado del teléfono móvil...) y romper con el sentido de fantasía, es decir, romper con la idea de conseguir todo a cambio de nada.

Y, por último, un anexo sobre cómo nació la paternidad proactiva. Este apartado tendría que leerse en primer lugar, para comprender el fundamento y justificación pedagógico-científico del modelo y, sobre todo, de la importancia de las experiencias vividas por las familias. Este modelo se fundamenta en teorías del desarrollo, investigaciones científicas, recomendaciones pediátricas y la propia experiencia de la autora con las familias, diferentes entre sí, con peculiaridades y modelos de actuación distintos, pero que tienen en común el sentimiento de amor, el apego y el vínculo emocional entre sus miembros que conforman un cóctel que, bien combinado, garantiza el éxito del modelo.

Ahora solo queda disfrutar de este magnífico libro.

Emilio Miraflores Gómez

Universidad Complutense de Madrid e.miraflores@pdi.ucm.es 